\title{
Adulterio femenino, divorcio y honor en la escena decimonónica española. El debate social en la recepción de El nudo gordiano, de Eugenio Sellés (1842-1926)
}

\author{
Female Adultery, Divorce and Honor in Nineteenth Century \\ Spanish Drama: Social Debate Surrounding the Reception \\ of El nudo gordiano, by Eugenio Sellés (1842-1926)
}

\author{
Francisco Checa Olmos \\ y Concepción Fernández Soto \\ Universidad de Almería
}

\section{RESUMEN}

El artículo muestra cómo en la España de la segunda mitad del siglo XIX el discurso de la estabilidad social y de la sumisión femenina — también llamado de la "domesticidad"— se asienta en el teatro a través de la representación de temas como el honor, el adulterio femenino, la honra y la muerte. Al mismo tiempo, el discurso teatral retroalimenta idénticos discursos ideológicos y morales - incluso psicológicos y legislativos - y sanciona los modelos de conducta que pretenden disolver el orden social burgués imperante. Como ejemplo metodológico se toma la obra El nudo gordiano, de Eugenio Sellés y Ángel, autor perteneciente a una generación de dramaturgos nacidos en torno a la década de 1840. El final propuesto por el autor, la muerte de la esposa adúltera, se situó en el centro de todas las reacciones inmediatas posibles, suscitadas entre espectadores, críticos y analistas, gacetilleros y especialistas, literatos y juristas, psicólogos o moralistas y personas de a pie. Por ello también se presenta la recepción crítica que la obra alcanzó, comprobando sus repercusiones sociales y literarias.

Palabras clave: Adulterio, Honor, Género, Teatro decimonónico, Eugenio Sellés.

\section{SUMMARY}

In the second half of 19th century Spain, discourse on social stability and female subordination - also referred to as "domesticity" - found its place in the theater through the representation of such themes as honor, female adultery, virtue and death. At the same time, theatrical discourse reinforced the current ideology and morality — even psychological and legislative discourse- and sanctioned behavioral models that sought to undermine the prevailing bourgeois social order. As a methodological example, we refer to the work entitled El nudo gordiano, by Eugenio Sellés y Ángel, one of a generation of playwrights born around the decade of the 1840s. The ending proposed by this author, namely, the death of the adulterous wife, occupied the center of all the possible immediate reactions, including responses from spectators, critics and analysts, authors and jurists, etc. For this reason we also discuss the critical reception of this work, taking note of its social and literary repercussions.

Key words: Adultery, Honor, Gender, 19th Century Drama, Eugenio Sellés. 
El objetivo central de estas páginas es mostrar cómo en la España de la segunda mitad del siglo XIX el discurso de la estabilidad social y de la sumisión femenina — también llamado de la "domesticidad" — se asienta en el teatro, a través de la representación de temas como el honor, el adulterio femenino, la honra y la muerte (casi siempre asesinatos originados por venganzas de honor). En este sentido, y al mismo tiempo, el discurso teatral retroalimenta idénticos discursos ideológicos y morales —incluso psicológicos y legislativos- y sanciona los modelos de conducta que se han de seguir en la lucha contra los elementos disolventes y disruptivos del orden social burgués imperante.

Hablamos del teatro y del entorno social que lo circunda, en un período en el que los escritores se presentan como portavoces de las aspiraciones de sus contemporáneos (el público), haciendo de los escenarios tribuna y de los personajes oradores; así que temas como los ideales de vida cristiana, la llamada relajación ética en determinados aspectos de la vida (como el honor y el adulterio), el valor del matrimonio y de la familia, la instrucción pública y la educación o la autoridad masculina, lo que en su conjunto bien podríamos denominar microsociología hispana, hicieron sentir a algunos dramaturgos la necesidad de elaborar un teatro de crítica social, incidiendo en las costumbres contemporáneas.

En esta coyuntura situamos a Eugenio Sellés y Ángel ${ }^{1}$, autor perteneciente a una generación de dramaturgos nacidos en torno a la década de los 40 (Enrique Gaspar en 1842, Leopoldo Cano en 1844, Ángel Guimerá en 1845, José Felíu y Codina en 1847 y Rosario de Acuña en 1851), grupo o más o menos homogéneo que, con sus particularidades personales, estrenaron sus primeras obras en los comienzos de la Restauración española y a la sombra del futuro Nobel, José Echegaray (1832-1916).

Es cierto que a lo largo de todo el siglo XX la investigación sobre Eugenio Sellés lo ha considerado un autor "menor"; así que la crítica a su teatro, mucho más en la actualidad, corre el riesgo de sustentarse sobre hipótesis que no siempre pueden ser avaladas por una bibliografía precedente amplia, ni siquiera sobre una bibliografía actualizada, a todas luces inexistente; por ende, el denominado "teatro de la Restauración" ha suscitado escaso interés para la crítica literaria y, cuando se ha hecho, ha sido partiendo del modelo de análisis negativizado que en su momento fue aplicado a sus predecesores por muchos miembros de la Generación del 98 - y después por la del 27-. Llama la atención que las investigaciones y críticas teatrales actuales hayan sido incapaces de explicar con criterios científicos el carácter propio del éxito

\footnotetext{
${ }^{1}$ El dramaturgo Eugenio Sellés y Ángel, Marqués de Gerona (Granada, 1842-Madrid, 1926) fue académico, ateneísta, periodista y político, se inició en el drama histórico bajo la tutela de José Echegaray, con obras como La torre de Talavera (1877) y Maldades que son justicias (1878), abandonando esta línea en la década de los 80 para intensificar la crítica de las costumbres sociales de su época, con El nudo gordiano (1878) y El cielo o el suelo (1880); asimismo participa en las polémicas sobre la introducción del Naturalismo literario en España, con obras como Las esculturas de carne (1883) y Las vengadoras (1884; 1892). Sus estrenos fueron altamente polémicos, intensificando en las postrimerías del siglo XIX una tendencia regeneracionista, como resultado de su posición ideológica ante la crisis de fin de siglo, estrenando La vida pública (1885) y La mujer de Loth (1896/1902). Así traspasó a su teatro cuestiones tan candentes como las emergentes luchas sociales y feministas. Para un estudio de conjunto de su evolución dramática en el contexto del debate social e ideológico de su época, véanse las tesis doctorales de C. Fernández Soto (2005) e I. Martín (1981); para aspectos más concretos, Fernández Soto (2009a; 2009 b).
} 
del que gozaron autores como Echegaray, Sellés y Cano. En este sentido el presente artículo nos parece del todo pertinente, pues, en parte, llena un vacío en el conocimiento de aquel teatro y aquella época.

Nuestra intención en estas páginas es, pues, resaltar el error que supone considerar aquel teatro de forma negativa, usando las lentes de espectador actual, y mostrar la importancia que en su día alcanzaron ciertas obras, en especial gracias al debate social que en torno a ellas se produjo. De entre todas, si hay una representación que ejemplifica ese éxito fue sin duda El nudo gordiano, de Eugenio Sellés (Teatro Apolo, 1874). Por ello se situó en el centro de todas las reacciones inmediatas posibles, suscitadas entre espectadores, críticos y analistas, gacetilleros y especialistas, literatos y juristas, psicólogos o moralistas y personas de a pie. Nadie quedó al margen ni fue ajeno al desenlace propuesto por su autor. La obra generó un debate social de tanta trascendencia que podemos considerarlo único en la escena finisecular española; por ello lo tomamos como ejemplo metodológico².

Al hilo de lo expuesto y tratando de responder al título mismo del trabajo, este queda dividido en dos partes. La primera expone cómo en la España finisecular el discurso de la estabilidad social se asienta en el teatro a través de la representación de temas como la honra/adulterio y la muerte, ejemplificado en el drama de Sellés, El nudo gordiano. Pero sabiendo que el discurso teatral no es ajeno a otros que también están presentes en el refuerzo de la domesticidad femenina —como el legislativo, moral, psicológico e ideológico- más bien se retroalimentan. A ello dedicamos la segunda parte, apoyándonos en la recepción crítica que la obra alcanzó, comprobando sus repercusiones sociales y literarias.

\section{HONRA, HONOR Y ADULTERIO. LA MUERTE COMO CLÍMAX DRAMÁTICO. EL NUDO GORDIANO, DE EUGENIO SELLÉS}

Para enfocar correctamente el tratamiento escénico del honor y el adulterio en el teatro de fines del siglo XIX en España, conviene no olvidar que la garantía de la estabilidad social burguesa estaba asegurada gracias al cuerpo legislativo vigente. Su conocimiento nos revela que por entonces la mujer sufría innumerables limitaciones, impuestas por ley³. Fue durante la Restauración cuando se consolidó eficazmente dicha discriminación legal ${ }^{4}$; su máxima expresión apareció en el Código Civil

\footnotetext{
${ }^{2} \mathrm{Su}$ recepción crítica solo es comparable a la que años después suscitarían estrenos como Juan José (de Dicenta, 1895) —un "drama de alpargata" con "gentuza y oliendo a vino", que como novedad presenta en el Teatro de la Comedia madrileño a un obrero como personaje principal, donde antes solo aparecían personajes de seda y levita- o Electra (de Galdós, 1901) —aprovechado su estreno en el Teatro Español para la expresión de la ira anticlerical en un momento convulso para la sociedad española-. El estudio y comparación de la recepción crítica de estas tres obras bien merecerían un análisis conjunto.

3 "Nobles o plebeyas, su condición femenina les suponía una serie de cortapisas legales, que aumentaron sensiblemente a medida que las recopilaciones y los códigos iban cediendo a la presión creciente de los ordenamientos romano y canónigo, y a medida que el derecho común se fue imponiendo en los antiguos territorios forales" (López-Cordón 1986: 79).

${ }^{4}$ Sobre la injusta aplicación de las leyes a la mujer y el doble rasero para sancionar sus actos, Scanlon (1976: 134) señalaba: mientras "la ley civil la trata como una menor necesitada de pro-
} 
de $1889^{5}$, en especial con la redacción de los artículos 22, 57, 58, 59, 60, 61, 70, 104, 105 y $154^{6}$. Estos y otros preceptos discriminatorios se detallan con profusión en Mary Nash (1983: 160-63).

Respecto al divorcio, que ya se había planteado en el Preámbulo a la "Ley de 18 de junio de 1870 sobre matrimonio civil", fue rechazado por considerarse que atentaba contra la estabilidad del hogar. Aunque tuvo sus defensores, la mayor parte de la opinión pública se manifestó en su contra (véase Scanlon 1976: 137). Ahora bien, la fuerte presión social y psicológica —y sobre todo económica- que la sociedad ejercía sobre la mujer para que contrajera matrimonio las dejaba en un callejón sin salida y, resignadamente, ellas aceptaban esa esclavitud legal ${ }^{7}$. Porque la obediencia de la esposa no solo se basa en la legalidad y la religión, sino que existe plena conciencia de la superioridad moral e intelectual del marido (véase López-Cordón 1986: 79). Tampoco las sucesivas legislaciones consiguieron avance alguno en ese sentido, perpetuando el papel tradicional de la mujer como garantía del mantenimiento del honor y la honra familiares ${ }^{8}$.

Veamos cómo la subalternidad de la mujer no solo está armada en el cuerpo legislativo, también tiene su correlato en la escena, con un código moral que ha venido sucediéndose en el teatro desde siglos anteriores ${ }^{9}$. A saber, en los orígenes de la literatura española el adulterio aparece como una superestructura dramática que engloba otros subtemas, como la fidelidad conyugal, el engaño y los celos, la virtud

tección frente a su propia fragilidad, la ley penal la considera como un adulto responsable, plenamente capaz de comprender las consecuencias de sus actos".

${ }^{5}$ Fue aprobado por Real Decreto de 24 de julio, según lo dispuesto en la Ley de 26 de mayo de 1889, a propuesta del Ministro de Gracia y Justicia, José Canalejas y Méndez, y sancionado por la reina regente María Cristina (madre de Alfonso XIII).

${ }^{6}$ Código Civil de 1889, en el artículo 57 se desarrolla la autoritas maritalis, que dispone que "el marido debe proteger a la mujer y esta obedecer al marido"; artículo 59: "el marido es el administrador de los bienes de la sociedad conyugal", también será el representante de su esposa, no pudiendo esta comparecer sin su licencia ni siquiera a un juicio, ni realizar compras - excepto las del consumo habitual familiar- o firmar contratos (art. 60) o enajenar sus bienes (art. 61), etc. Para la mujer casada le está reservado el papel de madre cuidadora de menores y de las demás hembras; artículo 70: "quedarán los hijos varones mayores de tres años al cuidado del padre, y las hijas al cuidado de la madre». El Código Civil en ningún momento contempla la disolución del matrimonio y asimila divorcio a separación (art. 104). Ante cualquier atisbo de adulterio este será causa de separación; se concederá siempre a petición del cónyuge inocente que alegue una causa legítima; sin embargo, en el adulterio de la mujer es "en todo caso", en el adulterio del marido será "cuando resulte con escándalo público o menosprecio de la mujer" (art. 105).

${ }^{7}$ No se olvide que las mujeres solteras quedaban mal situadas socialmente: la soltería estaba reservada solo para las prostitutas, enfermas o desfloradas, mujeres que tenían que atender a sus padres ancianos o que en su juventud tuvieron un noviazgo truncado.

${ }^{8}$ La falta de espacio nos impide profundizar en un tema tan estudiado como es el honor/la honra, no solo desde la antropología, también en su relación con el teatro. Remitimos a varias obras clásicas para que el lector pueda ampliar sus conocimientos sobre el particular: Artiles (1969); Castro (1916); Correa (1991); Gautheron (1992); Peristiany (1968) y Pitt-Rivers (1979).

${ }^{9}$ Sabemos que en el adulterio la mujer ha sido siempre el sujeto castigado, sin embargo, estudios actuales demuestran que a veces se ha revelado con todo y contra todos, incluso con violencia, hasta producir la muerte del varón; véase Sánchez-Pérez (2013). Para comprobar estos cambios de paradigmas de género, no solo para el período estudiado, también para décadas posteriores, véanse los ensayos recientes recogidos en las diferentes obras colectivas de NievaDe la Paz (ed.) 2009; Nieva-De la Paz, Wright, Davies y Vilches-De Frutos (eds.) 2008; Vilches de Frutos y Nieva-De la Paz (eds.) 2012. 
y la honra, la traición y la deshonra; si bien es cierto que por encima de todos se sitúa el honor, tratado casi siempre de forma burlesca o desde un punto de vista moralizante. Y como no podía ser de otra manera, el adulterio femenino, que se une directamente al honor del marido y la deshonra de la familia, presenta una variedad riquísima de motivos típicamente teatrales ${ }^{10}$, ofreciendo ya un amplio muestrario en el teatro del siglo de Oro.

Por su parte, la reformulación neorromántica de los temas sobre el honor aparece significativamente en el teatro más efectista y "Sangriento" de José Echegaray (su propuesta más espectacular en este sentido fue El Gran Galeoto, estrenada en 1881), quien a partir de su primer estreno se convierte en un conductor de temas y gustos teatrales, como vio muy acertadamente Deleito y Piñuela ${ }^{11}$.

En este ambiente aparece una obra que tras su estreno iba a llenar páginas de periódicos, revistas y críticas; podemos afirmar que después de El nudo gordiano la escena española del último cuarto del siglo XIX no volvería a ser igual. La obra de Eugenio Sellés se estrenó en el Teatro Apolo el 28 de noviembre de 1878 y consiguió permanecer ininterrumpidamente en cartel hasta el 19 de diciembre; veintitrés días, algo inusual para la época, enseguida se llevó por toda España y Latinoamérica. En sus papeles principales contó con los famosos actores Antonio Vico, Enrique Sánchez de León y Antonia Contreras. La publicación impresa alcanzó su decimoquinta edición en tan solo tres años, algo que también constituyó una excepción para la época, y fue ampliándose en años sucesivos.

¿Qué novedades presentaba este drama para alcanzar tal éxito? ¿No constituía una vuelta a la dramaturgia barroca? En apariencia así era. Con ella irrumpió en escena de nuevo el tema del adulterio femenino, pero en su planteamiento aparece de manera novedosa el divorcio, como una posible salida a la situación. Sin embargo, este no es el final que elige Sellés para Carlos, el protagonista, quien lejos de aceptar el divorcio mata de un disparo a su esposa y después, en un rasgo heroico, quema una carta que podría exculparle, pues en ella Julia explica su muerte como un suicidio. Finalmente, se encamina a la cárcel con el deber cumplido.

La inmensa popularidad que alcanzó esta obra nos lleva a pensar que, primero, el público estaba deseoso de temas polémicos de calado colectivo: adulterio, castigo de la adultera, conveniencia o no del divorcio; y, segundo, que en realidad el público madrileño del último cuarto del XIX prácticamente aún vivía anclado en los paradigmas morales barrocos.

Como decimos, es cierto que aquella sociedad andaba metida en debates sobre el divorcio y similares ${ }^{12}$. Sin embargo, estaba claro que se trataba de un asunto muy

${ }^{10}$ F. W. Chandler (1916: 102ss) llegó a establecer hasta treinta y seis situaciones distintas en la peripecia de dos hombres disputándose la esposa de uno de ellos, o de dos mujeres a uno de sus maridos.

${ }^{11}$ José Deleito y Piñuela trata de entender el éxito inexplicable del teatro de Echegaray y sus seguidores, relacionándolo con el carácter de la raza española, profundizando en las raíces literarias del honor y en la salud histórica de la moral vengadora, en un teatro que desde las propuestas barrocas de Lope y Calderón pasan por el Romanticismo y llegan a las reformulaciones neorrománticas que nos ocupan (Deleito y Piñuela 1920: 175-177).

${ }^{12}$ Hasta principios del siglo XX no se empezaron a oír voces claras en defensa del divorcio, alentadas, quizás, por el éxito de las campañas a favor del mismo en otros países. En 1903, 
comprometido, especialmente porque entraba en franca contradicción con la doctrina católica, según la cual el matrimonio es un sacramento - y no un contrato- indisoluble; lo máximo que la Iglesia podía aceptar era una separación de los cónyuges. Algunos juristas argumentaban incluso que el divorcio venía a ser como una herejía derivada de la Reforma protestante (Larroder 1887: 17). El divorcio, afirmaba E. González Blanco (1902: 142), era una ley apropiada para aquellos países que carecían de la superioridad moral de España, como los Estados Unidos —donde el sentimiento del honor femenino no existe- o Francia - donde las tres cuartas partes de los matrimonios están prostituidos-. Scanlon (1976: 142) recuerda la obra del doctor Niceto Alonso Perujo (1882: 70), canónigo de la catedral de Valencia, quien, argumentando en contra del divorcio, aseguraba que si bien la mujer pueda estar a merced de los caprichos de su marido, la posibilidad del divorcio la pondría a merced de algo peor: "de sus propios caprichos".

Todo este entramado sociocultural cobija el estreno de la obra El nudo gordiano. En las tertulias, en los cafés y en los periódicos se discutía poco de su mérito artístico y mucho del valor de la tesis que suscitaba, tratando puntos de vista antropológicos, psicológicos, morales y jurídicos (ver al respecto Álvarez Espino 1879; Utrilla y Calvo 1879; Santa Olalla y Tárrago 1879; Alas "Clarín" 1881; Pi y Arsuaga 1884; De la Revilla 1884, entre otros). En realidad, la obra sirvió como una catequesis moralizante que salvaguardara el orden social establecido: por un lado, se advertía de los peligros que suponía el pecado del adulterio de la mujer y de sus consecuencias disolventes para la familia y los hijos y, por otro, se exaltaban las virtudes del hombre como único garante de la estabilidad de la familia y el hogar, aunque fuera un "marido vengador".

Para una mejor comprensión de nuestra tesis, a continuación presentamos las líneas argumentales de El nudo gordiano, desde el planteamiento hasta el desenlace ${ }^{13}$.

Primer Acto: En un gabinete elegantemente amueblado tres representantes de la alta burguesía, Fernando (hermano de Julia), Severo (tío de Carlos) y Enrique (amigo y socio de Carlos), discuten sobre la finalidad del teatro; después, Fernando, con palabras veladas, deja planteada la murmuración que recae sobre Enrique. Se incorpora Carlos, casado con Julia y padre de María, quienes festejan el aniversario de su boda. Carlos es el marido-padre ejemplar, dedicado enteramente a su trabajo para que a su familia no le falte de nada. Frente a este, Julia aparece pintada con tintes de derrochona y coqueta.

Pronto aparece la carta que desencadena la intriga: los amigos de Carlos quieren sorprender a los enamorados en su cita ("sorprender a los pichones en el nido"), pero

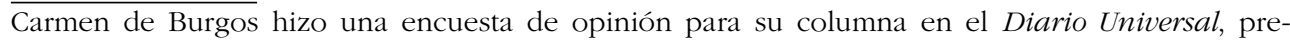
guntando a conocidas personalidades de la época acerca del divorcio. Se mostraron favorables Baroja, Blasco Ibáñez, Giner de los Ríos, Azorín y Octavio Picón; entre los contrarios destacan María de Echarri, Fernando Araujo, Pilar Rodríguez Contreras y Concepción Gimeno de Flaquer (dos feministas conservadoras); la Pardo Bazán y Gumersindo de Azcárate dieron respuestas evasivas. Algunas voces, como la de Pío Baroja, fueron más allá; en un artículo suyo — publicado en Alma Española, 10, 1903, pág. 2- rechazaba tajantemente la creencia generalizada de que "el adulterio en el hombre es una falta", mientras que "en la mujer es un crimen", tomando partido por la legalidad del divorcio, deseando que este prepare el camino para la unión libre, "la forma más perfecta, más acabada de la unión sexual" (véase Nash 1983: 21). La encuesta y sus términos están citados en Scanlon (1976: 144). Con todo el material de Burgos publicaría el libro El divorcio en España, 1904, que le sirvió para ganarse el sobrenombre de la "divorciadora".

${ }^{13}$ Citamos por la edición de la Sociedad de Autores, Madrid, 1915.
} 
él no quiere ese tipo de burlas y prefiere "Solucionar en privado el problema", exigiendo respeto en el hogar ajeno. De entrada se observa una solución progresista del adulterio: se considera reprobable, pero se resuelve en privado, desechando la sanción social, y se coloca en el lugar del esposo ultrajado. Sin embargo, a estas alturas del drama el espectador va adivinando que la adúltera va a ser precisamente Julia y su esposo el engañado.

Al fin Carlos la sorprende cuando acude a la cita con su amante, produciéndose el enfrentamiento de los cónyuges; en las acotaciones se describe la violencia de Carlos hacia su esposa. Le sobreviene un primer acceso de cólera y quiere golpearla; ella llama a su hija y esta, al interponerse, recibe el primer golpe, dirigido a su madre. La hija es la personificación de la inocencia, el adulterio la ruptura del sagrado orden familiar, del que la madre ya ha quedado expulsada.

A partir de ese momento el conflicto familiar pasa a ser social: Carlos pondrá en consideración de Severo y Fernando cuál debe ser el código de conducta a seguir cuando se ha perdido "honra, dicha, corazón,/ tesoros inmateriales,/ lo que no devuelve el celo/ de un juez, ni el propio trabajo,/ porque lo formó aquí abajo/ una bendición del cielo" (Acto Primero, Escena XIII, pág. 30). Julia, finalmente, es expulsada del hogar, provocando el dolor de la hija.

Segundo Acto. Salón de baile en casa de Severo; como este aún quiere reconciliar al matrimonio, planea, junto a Fernando, un baile para la puesta de largo de María, al que invitarán al matrimonio por separado. Julia, que desea el encuentro con su hija, ruega a Enrique que las deje a solas, pero este reacciona con furia, sospechando que a quien desea ver es a Carlos, porque aún lo ama. En un largo parlamento, Enrique, su amante, le expresa la fuerza desbordada de su amor, ignorando las convenciones sociales y la prudencia que ella le recomienda. Pero en estas circunstancias Julia, como recoge un amplio monólogo, ya desea más ser "esclava de la virtud" que "libre para el vicio".

En el encuentro entre madre e hija, esta le refiere que ha sido testigo de una conversación en la que se hablaba de una mujer que arrastraba su deshonra por los salones sociales. Le asegura con cuánto horror las escuchaba y cuánto desprecio sentía por esa mujer al oír "Que siempre el amante es/ el vengador del marido" (Acto Segundo, Escena V, pág. 44). Su propia hija se ha convertido también en juez moral del comportamiento de Julia; el dolor y arrepentimiento lo manifiesta su madre de manera más intensa.

Entretanto, se va fraguando en Carlos el clima de la venganza, al más puro estilo calderoniano. Paulatinamente el sentimiento de vergüenza se irá apoderando de él al ver cómo su deshonra es pública y que la separación solo ha servido para "dejar libre" a la adúltera y "airear" su nombre y deshonor delante de todos. El eco de la "falta de Julia" es vox populi, hasta Severo ha descubierto el lance entre Julia y Enrique, pero le pide a Carlos que trate de respetar las convenciones sociales y las apariencias. En esta situación inicia la búsqueda desesperada de salidas que reparen su honra y reconstruyan su identidad masculina. Severo le habla de la separación, pero Carlos le demuestra que en ese primer intento ha fracasado.

Carlos está decidido a matar a Enrique, pero cuando Julia se interpone para que la mate a ella, la respuesta a la adúltera es: "Ahora de un golpe, la suya!/ Y la tuya, poco a poco!» (Acto Segundo, Escena XVI, pág. 63). 
Tercer Acto: Severo y Fernando hablan sobre la situación extrema del encierro de Julia, quien ya lleva un mes sin ver a nadie. Fernando, su hermano, aprueba la medida para preservar su decoro, aunque, Severo, personaje conciliador, augura un mal fin para la pareja y aprueba la decisión de Julia de pedir el divorcio; ella está cada vez más asfixiada, y ya sabe que en el duelo mantenido entre Enrique y su marido, este ha sido herido por una estocada.

La adúltera empieza a sufrir y a expiar sus culpas de forma dolorosa, así que decide romper sus ataduras de una manera drástica, pensando en huir o, incluso, en el suicidio. Ninguna cosa es fácil, dado el muro inflexible que Carlos va construyendo alrededor de ella. Le suplica que le dé la libertad, que "rompa el nudo triste». Carlos se niega vehementemente y Julia recurre al amparo de la ley, pero de nada le vale. Cuando lee el papel en el que Julia ha dejado escrito su voluntad de suicidarse, lo arroja desdeñosamente sobre la mesa, y le dice: «iMujer, solo tienes brío/ para matar el honor!» (Acto Tercero, Escena IV, pág. 73).

Julia, llena de dolor por el desprecio y la frialdad de su marido, viéndose atrapada entre la falta de libertad y la propia vergüenza de sí misma, piensa que solo le queda ya la opción de la huida; sabe que así caerá en el estado primitivo y natural del vicio y la pasión, en el estado de "lo otro".

Sellés sabe que ha puesto en escena una catequesis moral y plástica, a fin de mostrar el modelo femenino que no se debe seguir, dadas las consecuencias destructivas que lleva consigo; su ideario es "mostrar el vicio para aborrecerlo". En ese momento la protagonista ya asume su condición de mujer perdida: ha traspasado plenamente la frontera de lo establecido y se ha situado en la frontera de "lo primitivo". Según Trullo-Herrera (1991: 82), "la recaída de la mujer en el mundo primario al que, en rigor, nunca ha dejado de pertenecer, la sitúa en la monstruosidad del arquetipo, a la vez dentro y fuera de la sociedad".

Pensamos que muy bien podría haber terminado el drama ahí, y hubiera tenido igual fuerza moralizadora para los espectadores, pero Sellés cree que ha de continuar en su planteamiento escénico hasta la muerte de la adúltera. Se acentúa la línea melodramática que va preparando el final, cuando Julia se despide desgarradoramente de su hija y le recomienda que cuando se case ejerza bien su papel de «mujer buena", haciendo de su hogar un templo sagrado. Por su parte, Carlos sigue debatiéndose entre el deber, la piedad, el amor hacia su hija, incluso hacia Julia, aunque ya va cobrando todo el protagonismo el móvil dramático de la restauración del honor.

El dramaturgo debe justificar la cruenta acción final de Carlos, apelando a los dictámenes de la naturaleza: se asoma al balcón, contempla el encuentro de Julia con su amante y el homicidio es inminente. Va en busca de una pistola para matar a su esposa: «Si es tarde...? Salve el honor/ mi muerte: ella o yo esta vez!/ ¡Naturaleza, eres juez,/ y me hacen tu ejecutor" (Acto Tercero, Escena VIII, pág. 80).

Se oye un disparo. Entra Carlos y asegura que Julia no se ha suicidado, que el uxoricida ha sido él. Carlos pide a Severo y Fernando que amparen la orfandad en la que queda su hija. Fernando se duele del dolor de María y le pregunta a Carlos: ¿¿Y la honra del hogar?", a lo que este contesta categóricamente con la famosa frase que cierra el drama: «Se va a la cárcel conmigo!» (Acto Tercero, Escena última, pág. 85-86).

Es palmario que debido al adulterio femenino se ha destruido el ideal de una familia armónica, compuesta por un esposo — cabeza de familia y principal proveedor 
de ella—, una esposa — garante de la armonía del hogar y la crianza de los hijos— y la prole. Ahora se invierten los términos, el homicida se convierte en héroe, aunque la ley lo castigue con la cárcel, pero entra en ella con la mirada alta y el honor recobrado.

¿Y en qué definición social ha ido encajando el modelo de mujer adúltera? ¿No quedaba otra solución dramática para ella que la muerte? La consideración del adulterio como "pecado" dejaba abierta la puerta al perdón del marido, bien por amor o por conveniencia personal. Y como corolario, en el marco de la moral cristiana, cabía también considerar el arrepentimiento de la adúltera. Pero, ¿por qué se contraviene esta moral cristiana? ¿Por qué se sigue más un modelo pesimista, al estilo de Dumas hijo y otros, que atienden más a las leyes del honor, aconsejando al marido de la adúltera ;Matalá!? Quizá porque no se sabe ni se puede crear todavía un modelo de mujer nueva que reconstruya su vida, a partir de esa falta que la dejará marcada para siempre, o quizá porque es más ejemplarizante aquella solución.

Parece demostrado en esta propuesta teatral que el acto de trasgresión femenina es imperdonable, incluso desde la perspectiva de quien lo comete. No conlleva ninguna satisfacción, porque arrastra a la perdición, al "fango", así deberá purgar el pecado en la escena misma, ya que al espectador habrá que presentarle una solución clara.

Por nuestra parte, estamos convencidos de que un dramaturgo de tesis como fue Sellés no deseaba presentar la vida tal cual es, cargada de realismo, ni extraer significados ni inferencias implícitas en ella, más bien quería probar algo nuevo en la escena; por ello maneja los personajes e incidentes únicamente con miras a conseguir su propósito: la venganza de una ofensa tras la ruptura del honor familiar, dado que sin ella la identidad masculina no puede subsistir ni limpiarse ${ }^{14}$.

Según Jo Labanyi (1990: 30-33), la nueva movilidad social y sexual después de la Revolución del 68 resultó en España en la desintegración del marco socio-simbólico que antes separaba centro y margen, civilización y barbarie, lo legítimo y lo ilegítimo. Desde esta perspectiva de estudio, nada más caótico y trasgresor que el adulterio femenino; por ello estamos de acuerdo con la definición que Tony Tanner (1979: 13) ofrece de adulterio, al concebirlo como "el acto de cruzar una frontera prohibida". Si la sociedad, para su existencia, depende del establecimiento de límites, el adulterio, al mezclar cosas que no deben ser mezcladas, representa una disolución de esos límites.

Para la mujer —esposa y madre, antes que mujer - el acto de "cruzar las fronteras" constituye un cuestionamiento de estos roles y, por ende, un acto de trasgresión imperdonable desde la perspectiva de la sociedad patriarcal. La mujer adúltera no es ni "esposa" ni "prostituta" en un sentido absoluto: desafía todas las categorías de la definición social impuesta por la sociedad burguesa. De ahí que la crisis del contrato social represente nada menos que una crisis en el sistema de significación: la mujer

\footnotetext{
${ }^{14}$ Los estudios recientes sobre género $y$ fin de siglo se han centrado en la inseparabilidad entre la política cultural y la sexual en la Europa finisecular. Ver al respecto Gilman Sander (1985: 72-96), Sally Ledger (1995: 22-24) o Elaine Showalter (1990). Para otros ámbitos, como el contexto español, véase el estudio de Kirpatrick (1995: 95-101) o para el argentino Minelli (2008).
} 
adúltera supone un desafío al significado del matrimonio y de los roles sexuales, y los somete a una reinterpretación (Tanner 1979: 363-364). Por tanto, esta figura femenina no solo refleja las tensiones sociales en torno al rol femenino en el matrimonio, la maternidad, la familia y la transmisión de la propiedad (Overton 1996: 14), sino que también llama la atención sobre la arbitrariedad de las estructuras y leyes que participan en la construcción del discurso realista burgués.

Sellés aclara las consecuencias destructoras del adulterio femenino para las bases sociales, pero aún queda una segunda cuestión en el aire sin responder, como es, ¿pese a todo, El nudo gordiano podía entenderse como un alegato a favor del divorcio? En realidad, Carlos sería exonerado de este asesinato por las leyes de la sociedad, que casi lo justifica. Ahora bien, advertimos algunas novedades en la presentación de esa familia destrozada por la tragedia de las circunstancias, a estas alturas de la década de los 70 del siglo XIX. Esto es, ¿qué falla en la sociedad para que Carlos y Julia no tengan la oportunidad de disolver su desgraciado matrimonio a través del divorcio? Quizá el problema radique en la incapacidad de Carlos para reconocer que su matrimonio está acabado, que no se puede resucitar y que quizá la solución venga por el divorcio — tan negado por él mismo y más asumido en Julia — aunque su actitud suponga una destrucción de las bases tradicionales de la sociedad española, algo que estaba claro que todavía no se podía presentar en la escena de 1878 .

Richard B. Klein (1981: 175) asegura que Eugenio Sellés se muestra favorable a aumentar el laicismo que podría liberalizar el pensamiento futuro, tratando de mostrar con fuerza su opinión de que el pasado histórico debe olvidarse, dada su anticuada perspectiva en los problemas sociales. Resalta el crítico también el uso de las técnicas psicológicas para caracterizar el comportamiento de los personajes, y así encuentra más justificación en la huida de Julia y Enrique, que en las actitudes de Carlos, atrapado en su vano afán de mantener su respetabilidad social, y afirma: "Sellés, al mostrar la necesidad del divorcio en estos casos indicó que la moralidad, divorcio en este caso, debe ser relativa a las necesidades de cada época. [...] El mensaje de Sellés es moderno, aunque su técnica dramática sea anticuada".

\section{LA RECEPCIÓN CRÍTICA. REPERCUSIONES SOCIALES Y LITERARIAS}

Como ya hemos mencionando, este estreno no dejó indiferente a nadie, de ahí la importancia que el drama adquiere en sí mismo y como transmisor de la ideología reinante. Esto es, las dimensiones de sus apreciaciones nos sitúan en un lugar privilegiado para comprender por dónde respiraba la sociedad madrileña del último cuarto del siglo XIX y, con ella, toda la literatura paralela que la obra generó. No podemos, por falta de espacio, presentar toda la problemática que esta obra suscitó en la prensa del momento, que nos permitiría comprobar las reacciones más inmediatas sobre ella (véase al respecto un estudio completo en Fernández Soto 2005: 251-257; 581-610).

De manera sucinta presentamos algunos ejemplos significativos y variados en las opiniones críticas del krausista Álvarez Espino y en las críticas literarias de Leopoldo Alas "Clarín", Manuel de la Revilla y Pi y Arsuaga. Muchas de sus apreciaciones coinciden con las que abundaban en manuales y guías al uso que restringían la educa- 
ción femenina a la exposición de sus deberes domésticos y a una guía de buenos modales como preparación al matrimonio ${ }^{15}$.

Álvarez Espino (1879: 77-78) insiste en que la grandiosidad del éxito del drama se debe a la antigüedad del problema del honor/adulterio, presentándonos gráficamente la disparidad de reacciones que suscitó:

desde aquellos que han visto en la obra de este dramaturgo un ataque manifiesto a la santidad del matrimonio y una crítica dura de la indisolubilidad con que le sella la Iglesia Católica, hasta los que han creído ver en ella el consejo y aún la justificación del parricidio, en los casos de adulterio; desde aquellos que la han considerado como la acertada expresión del realismo dramático y término prudente en que debe conciliarse la prosa insulsa de la vida y los horripilantes extremos del puñal y el veneno, hasta cuantos le juzgan como síntesis admirable del realismo y el idealismo dentro de la armonía estética que reclama el arte y le entienden como una crítica justa y provechosa de nuestras falsas ideas sociales respecto del honor, y de nuestros vacíos y nuestras imperfecciones legales respecto al matrimonio.

Desbrozando la trama de El nudo gordiano, Álvarez Espino analiza psicológicamente los móviles de los personajes para comprender su situación dramática. A su parecer, todos obran dentro de la lógica, menos Julia, a quien califica de "personaje poco real"; asimismo expone que hubiese sido más creíble que Carlos hubiera perdonado a su mujer, ejerciendo el "pedagogismo moral" necesario. A continuación, exhorta a los moralistas para que sean ellos los que solucionen el problema, sobre todo intensificando el peso de la mujer y sus pecados, por las consecuencias que el desorden y el vicio acarrean para la destrucción de la familia (Álvarez Espino 1879: 77-78).

El crítico Manuel de la Revilla (1884: 230-238) habla del tema del adulterio como uno de los que más interés suscitan y como fuente inagotable de producciones dramáticas, "siempre que se lleva al teatro despierta interés por su planteamiento y solución final, ya que afecta al individuo y a la sociedad". Revilla alaba la novedad del planteamiento de Sellés que parece romper con las propuestas dramáticas del momento y contra la misma sociedad que no deja salidas honrosas al marido ultrajado: "la sociedad quiere que la honra no resida en el esposo, sino en la mujer, que la vende al primer advenedizo, y que el deshonor no resida sobre el que peca, sino sobre el que sufre las consecuencias del pecado" (1884: 235).

El planteamiento de Manuel de la Revilla parece coincidir con el del protagonista del drama, pues todas las salidas que la sociedad ofrece al marido le parecen incompletas, todos los planteamientos que presenta le llevan indefectiblemente a justificar el homicidio de Carlos, ya que "la moral aprueba el homicidio cometido en defensa de la vida, ¿por qué no aprobarlo cuando se comete en defensa de la honra, que vale más que aquella? (1884: 237). Y concluye:

por eso, sin atrevernos a decidir si en el terreno de la moral abstracta es lícito el acto del protagonista de El Nudo Gordiano, no titubearemos en aconsejar a los que se hallen en

\footnotetext{
${ }^{15}$ Como decimos, el impacto de su estreno fue tan grande que los abogados Nicolás Santa Olalla y José María Tárrago (1879) dedicaron una obra para desmontar, desde el punto de vista jurídico, el final que E. Sellés elige para su drama. Sus ataques y razonamientos los dividen en dos partes, "ante la ley" y "ante la moral». En Fernández Soto (2005: 601-606) se trata este tema con profundidad.
} 
su caso que, mientras el divorcio no venga, ¿por qué no decirlo?, a moralizar el matrimonio, o al menos a remediar sus males, corten el nudo gordiano con la espada que en sus manos pone la ley del honor (de la Revilla 1884: 238).

L. Alas "Clarín" (1881), conocedor del drama de Sellés y de la obra crítica de los abogados Santa Olalla y Tárrago, le dedica uno de sus Solos. Trata de marcar al respecto su posición de librepensador y anticlerical, observando que un drama no es un tratado legal sobre la causa del adulterio, y hace hincapié en que la solución dramática de Sellés es un alegato en contra de los defectos y contradicciones sociales; por ello asegura que Sellés no aconseja matar a la cónyuge infiel. Establece un paralelismo con El médico de su honra, de Calderón, El castigo sin venganza, de Lope, o uno más próximo, Drama nuevo, de Tamayo y Baus. Aplaude, por ende, los valores artísticos más que la verosimilitud de la solución final del drama: "la belleza no está en el pistoletazo, sino en la expresión, en la forma que le da el poeta" (Alas 1881: 111).

Se muestra de acuerdo con Sellés cuando dice que este no apadrina la conducta de Carlos, más bien lo presenta "como víctima de los defectos sociales del día" (Ibid: 112) y responsabiliza de estos defectos a todos los hombres que pueden tomar la iniciativa en las reformas morales y jurídicas. Expone su empatía con el personaje masculino, alabando el acierto de Sellés al encarnar en Carlos un tipo heroico que lucha contra las adversidades sociales y las costumbres impuestas, un tipo de héroe que siempre conecta con el público. Carlos lucha como un titán para sacudirse el papel indigno de marido engañado que la sociedad le impone:

Carlos tenía un hogar [...] y el honor, el verdadero, le dice: avéntalo, quema sus pajas, quédate sin hogar [...] y Carlos cumple el deber que le impone su honor y destruye con sus manos el hogar querido. Queda una víctima inocente, su hija María, y 'una sombra en el cuadro', Julia" (Alas 1881: 117).

Al hacer apreciaciones subjetivas sobre los personajes, "Clarín" carga sus acusaciones moralistas sobre la debilidad del carácter de Julia y su sumisión al dictado del placer, olvidando su deber. Al privarla Carlos de su libertad, para encarcelar su honor, el amor para Julia está en la calle esperando; siempre se huye de un presidio, si se puede, y la libertad y el vicio juntos pueden más que el deber y que María: Julia huye y Carlos la mata; esa es la fatalidad moderna, la fatalidad horrible de la lógica" (Alas 1881: 118). Por último "Clarín" se centra en desmontar la crítica al drama que había aparecido en el diario ultraconservador El Siglo Futuro, desde donde se propugnaba también la indisolubilidad del matrimonio como vínculo sagrado y contrato ceremonial.

Por último exponemos los argumentos que presenta al respecto Pi y Arsuaga (1884: 119-151). Para él también es absurda la situación que ofrece Sellés, al tratar de resolver un problema social por medio de violentas situaciones: "en El nudo gordiano hay tanta exuberancia de poesía como falta de sentido común" (Ibid.: 119). ¿Qué merece la mujer adúltera? ¿Por qué medios la dignidad y el honor del marido infamado deciden o dejan decidir la cuestión sin malearse ni sufrir menoscabo? El crítico descarta todas las soluciones legales y, partiendo de la base de la indisolubilidad moral del matrimonio - con la ley y sin la ley- tampoco acepta el divorcio, ni siquiera estando las partes de acuerdo. En consecuencia, vuelve a plantear el mismo callejón sin salida, dado que tampoco acepta la solución jurídica para un hombre que ha sido engañado por su mujer. 
La reconciliación también se hace imposible, toda vez que la dignidad de Carlos no puede ser restituida por ninguna ley. Tampoco la separación es una posibilidad que pueda romper el nudo, dado que el remedio de desatarlo solo sería al precio de "fomentar el adulterio". Además de que el legislador puede avanzar en todo lo que quiera pero no en temas del corazón: "en cuestiones del sentimiento su decisión es nula". La ley solo debe valer para garantizar la paz de la familia, para que el adulterio dañe lo menos posible. La ley no puede hacer más, y tampoco se debe pensar que el ofendido va a tener a la libertad de castigar a la adúltera, pues sería para muchos el adulterio una coartada para conseguir fines más oscuros y peligrosos, de crimen y barbarie (Pi y Arsuaga 1884: 143). Para este crítico la solución que Sellés propone está plenamente justificada, pero jamás podría entenderse como aplicable para todos los casos. Ahora bien, "Sellés no deshace el nudo, sino que se rompe, en un acto violento, que, a lo sumo, puede parecer disculpable" (Ibid.: 149).

\section{CONCLUSIONES}

Acabamos de mostrar que la literatura, y en especial el teatro en el siglo XIX - género social por excelencia, debido a su dimensión espectacular y de recepciónconstituye una fuente importante para el conocimiento socio-histórico de la época en la que se inserta, contribuyendo a interpretar las estructuras emocionales propias de entonces, el universo simbólico imperante, los imaginarios colectivos, los valores — morales y estéticos - con los que la población interactúa.

En este sentido, la elección de un drama como El nudo gordiano, junto al estudio de su recepción crítica y social, nos sirve como un rentable y eficaz método de análisis, no solo literario, también histórico y socio-antropológico, dado que, como decimos, su trama y desenlace ofrecen suficientes variables culturales para comprender las formas de vida, las actitudes, las creencias, aceptaciones y rechazos respecto a los comportamientos humanos de entonces. De ahí que su desenlace, tal como sea aceptado y/o rechazado por los espectadores y la crítica, es la mejor muestra para saber cómo se entendían las relaciones matrimoniales, el honor y cómo se combatía el adulterio, el qué dirán social, la dicha y la vergüenza de un hombre y una familia, el papel del varón frente a la mujer, la legalidad y la ilegalidad, la moral —individual y colectiva-, la felicidad frente a la desdicha, en definitiva, la honra frente al deshonor, la muerte frente a la vida.

De forma muy significativa una obra dramática como El nudo gordiano, con ese gran calado crítico en su recepción, nos centra adecuadamente el tipo de discurso que la burguesía finisecular mantenía respecto a la situación de la mujer en la sociedad: la inferioridad reflejada en el ámbito de lo legal y lo social, lo moral y familiar. Dado el régimen de tutela masculina en el que se desarrollaba la vida femenina, el divorcio no puede entenderse más que como un acto peligroso, desestabilizador de la familia, rompedor de las estructuras sociales. En otros términos, el marco legítimo donde se desarrolla la vida y actividad vital de la mujer casada - estatus al que todas ellas deben aspirar - queda cercenado con el divorcio, por ello se presenta como inaceptable.

Si el destino personal y social de la mujer es la familia - aquí ella es la mantenedora y transmisora de la moral, la honra y el estatus del que es depositaria- socialmente 
está justificado el rigor con el que se han de juzgar sus conductas trasgresoras. Su función radica en interpretar a la perfección los papeles de esposa y madre, espejo donde la sociedad mirará y juzgará a toda su familia. Por ello es sancionada si no está a la altura de lo que se espera de ella.

El teatro cumple eficazmente con su función "tranquilizadora" y así la ideología de la domesticidad es llevada al extremo: "¿Y la honra del hogar?". Carlos contesta: «iSe va a la cárcel conmigo!»

\section{BIBLIOGRAFÍA CITADA}

Alas "Clarín", L. 1971. "El nudo gordiano de Sellés", en Alas, L., Solos de Clarín: 111-123. Madrid: Alianza Editorial [1881].

Alonso Perujo, N. 1882. El matrimonio canónico y el matrimonio civil bajo el punto de vista teológico, canónico, político y social, Madrid: Imprenta del Sr. Lezcano y Compañía.

Álvarez Espino, R. 1879. Ensayo histórico-crítico del Teatro español (Precedido de un Prólogo del Excmo. Sr. D. Francisco Flores Arenas). Cádiz.

Artiles, J. 1969. Bibliografía sobre el problema del bonor y la bonra en el drama español en Filología y Crítica bispánica. Madrid: Ediciones Alcalá.

Castro, A. 1916. Algunas observaciones acerca del concepto del bonor en los siglos XVI y XVII. Madrid: Imprenta de los sucesores de Hernando.

Correa Mújica, M. 1991. "El campesinado y el concepto de honor en El Alcalde de Zalamea de Pedro Calderón de la Barca". Letralia 70 [17 de mayo].

Chandler, F. W. 1916. "The eternal triange", en Aspects of modern drama. Nueva York: The Macmillan Company.

Deleito y Piñuela, J. 1920. Estampas del Madrid teatral fin de siglo, vol. I. Madrid: Saturnino Calleja.

De la Revilla, M. 1884. "Tendencia docente en la literatura contemporánea", en Obras Completas: 144-145. Madrid: Imprenta Central.

Fernández Soto, C. 2005. Claves socioculturales y literarias en la obra de Eugenio Sellés y Ángel (18421926). Una aproximación al teatro español de finales del siglo XIX. Almería: Universidad de Almería.

Fernández Soto, C. 2009a. "La mirada hacia la mujer en la dramaturgia de Eugenio Sellés (1842-1926): madres, esposas, hijas, hijastras y ángeles de alas rotas". Stichomythia. Revista de Teatro Contemporáneo 8: 108-126.

Fernández Soto, C. 2009b. "Eugenio Sellés (1842-1926) ante la renovación teatral de 1900: gente vieja frente a gente nueva". Hecho Teatral. Revista de teoría y práctica del teatro bispánico 9: 119-143.

Gautheron, M. (ed.). 1992. El honor. Imagen de sí mismo o don de sí, un ideal equívoco. Madrid: Cátedra.

González Blanco, E. 1902. "La ley de divorcio y sus inconvenientes". España Moderna 14, 166 (octubre): 142 .

Labanyi, J. 1990. "The Problem of Framing in La de Bringas". Anales Galdosianos 25: 30-33.

Larroder y Lamaignere, L. 1887. El divorcio y el socialismo ante el derecho político. Madrid: Imp. de Ulpiano Gómez y Pérez.

Ledger, S. 1995. "The New Woman and the Crisis of Victorianism", en Ledger, S. y

López-Cordón, Mํ V. 1986. "La situación de la mujer a finales del Antiguo Régimen", en Durán, M. A. y otras (eds.), Mujer y sociedad en España (1700-1975): 47-108. Madrid: Dirección General de Juventud y Promoción Socio-cultural.

Kirpatrick, S. 1995. "Gender and Difference in Fin de siglo Literary Discourse", en Colmeiro, J. y otros (eds.), Spain Today: Essays on Literature, Culture: 95-101. Hannover: Dartmouth College.

Klein, R. B. 1981. "Harbinger of future themes: Selles'1878 plea for divorce in Spain". Romance Notes 22 (2): 171-176.

Martín Fernández, Maㅗ I. 1981. Lenguaje dramático y lenguaje retórico. (Echegaray, Cano, Sellés y Dicenta). Cáceres: Universidad de Extremadura. 
Minelli, M ${ }^{\mathrm{a}}$ A. 2008. "Cinceladas para su estreno. Representación literaria de las mujeres a fines del siglo XIX". La Aljaba 12: 71-83.

Nash, M. 1983. Mujer, familia y trabajo en España, 1875-1936. Barcelona: Anthropos.

Nash, M. 2004. Mujeres en el mundo. Madrid: Alianza Editorial.

Nieva-De la Paz, P. (ed.). 2009. Roles de género y cambio social en la literatura española del siglo $X X$. Amsterdam: Rodopi.

Nieva-De la Paz, P., Wright, S., Davies, C. y Vilches-De Frutos, F. (eds.). 2008. Mujer, literatura y esfera pública: España 1900-1940. Philadelphia: Society of Spanish and Spanish-American Studies.

Oostendorp, H. Th. 1969. "El sentido del tema de la honra matrimonial en las tragedias de honor". Neophilologus 53 (1): 14-29.

Overton, B. 1996. The Novel of Female Adultery. Nueva York: St. Martin's Press.

Peristiany, J. G. (ed.). 1968. El concepto de honor en la sociedad mediterránea. Barcelona: Labor.

Pitt-Rivers, J. 1979. Antropología del honor y politica de los sexos. Barcelona: Crítica.

Pi y Arsuaga, F. 1884. Echegaray, Sellés y Cano. Madrid: Imp. de Alfredo Alonso.

Sánchez-Pérez, M. 2013. "El adulterio y la violencia femenina en algunos pliegos sueltos poéticos del siglo XVI. Revista de Dialectología y Tradiciones Populares LXVIII (2): 287-303.

Sander, G. 1985. "Sexology, Psycoanalisis, and Degeneration: From a Theory of Race to a Race to Theory", en Chamberlin, J. E. y Sander, G. (eds.), Degeneration: The Dark Side of Progress: 7296. Nueva York: Columbia University Press.

Santa Olalla, N. y Tárrago, J. Ma . 1879. "El nudo gordiano" del señor Sellés, ante la ley y la moral. Madrid: Montes, Torres y C. ${ }^{a}$.

Scanlon, G. C. 1976. Las polémicas feministas en la España contemporánea (1868-1971). Madrid: Siglo XXI.

Sellés y Ángel, E. 1915. El nudo gordiano. Madrid: Sociedad de Autores [1878].

Showalter, E. 1990. "Bordelines", en Sexual Anarchy, Gender and Culture at the Fin de Siècle: 1-18. Nueva York: Viking Penguin.

Sirera, J. L. 2003. "El paradigma femenino en el teatro español del siglo XIX". Stichomytia. Revista de teatro contemporáneo 1: 2:20.

Tanner, T. 1979. Adultery in the Novel: Contract and Transgresion. Baltimore: The Johns Hopkins University Press.

Trullo-Herrera J. L. 1991. "Mujer de perdición", en Arquetipos teatrales y convenciones sociales: 7388. Barcelona: PPU.

Utrilla y Calvo, F. 1879. "La moral de El nudo gordiano". Revista de España [s.p.]. Madrid.

Vilches de Frutos, M ${ }^{a}$ F. y Dougherty, D. 1992. "El teatro y sus instituciones. La escena madrileña entre 1900 y 1936. Apuntes para una historia del teatro representadon. ALEC 17: 75-86.

Vilches de Frutos, M ${ }^{a}$ F. y Nieva-De la Paz, P. (eds.). 2012. Imágenes femeninas en la literatura española y las artes escénicas (siglos XIX y XX). Filadelfia: Society of Spanish and Spanish-American Studies.

Fecha de recepción: 3 de junio de 2013

Fecha de aceptación: 19 de marzo de 2014 